(c) American Dairy Science Association, 2006.

\title{
Major Advances in Globalization and Consolidation of the Artificial Insemination Industry
}

\author{
D. A. Funk \\ ABS Global, Inc., DeForest, WI 53532
}

\begin{abstract}
The artificial insemination (AI) industry in the United States has gone through many consolidations, mergers, and acquisitions over the past $25 \mathrm{yr}$. There are 5 major AI companies in the United States today: 3 large cooperatives, 1 private company, and 1 public company. The latter 2 have majority ownership outside of the United States. The AI industry in the United States progeny-tests more than 1,000 Holstein young sires per year. Because healthy, mature dairy bulls are capable of producing well over 100,000 straws of frozen semen per year, only a relatively small number of bulls are needed to breed the world's population of dairy cows. Most AI companies in the United States do not own many, if any, females and tend to utilize the same maternal families in their breeding programs. Little differences exist among the selection programs of the AI companies in the United States. The similarity of breeding programs and the extreme semen-production capabilities of bulls have contributed to difficulties the AI companies have had in developing genetically different product lines. Exports of North American Holstein genetics increased steadily from the 1970s into the 1990s because of the perceived superiority of North American Holsteins for dairy traits compared with European strains, especially for production. The breeding industry moved towards international genetic evaluations of bulls in the 1990s, with the International Bull Evaluation Service (Interbull) in Sweden coordinating the evaluations. The extensive exchange of elite genetics has led to a global dairy genetics industry with bulls that are closely related, and the average inbreeding level for the major dairy breeds continues to increase. Genetic markers have been used extensively and successfully by the industry for qualitative traits, especially for recessive genetic disorders, but markers have had limited impact for quantitative traits. Selection emphasis continues to migrate away from production traits and towards nonproduction traits, especially to-
\end{abstract}

Received September 1, 2004.

Accepted October 11, 2004.

E-mail:dfunk@absglobal.com wards health and fitness traits. Specifically, fertility has arguably become the major breeding and management issue facing dairy farmers today. Some producers have implemented crossbreeding programs in an effort to capitalize on heterosis, and crossbreeding will almost certainly need to be a bigger part of the AI companies business in the years ahead.

Key words: progeny test, genetic marker, Interbull, inbreeding

\section{INTRODUCTION}

The AI industry of today looks considerably different from the AI industry of 25 yr ago. Back in 1981, most of the AI companies in the United States were regional domestic cooperatives. In the $1980 \mathrm{~s}$, there was a period of tremendous industry growth, largely driven by a strong export market for semen, especially Holstein semen. In 1981, member organizations of the AI industry trade association, the National Association of Animal Breeders (NAAB), produced 15.5 million units of semen, of which 2 million units $(13 \%)$ were exported. Today, the member organizations of NAAB produce 28 million units of semen, of which 9 million units (30\%) are exported.

The importation of elite North American genetics into developed dairy countries, especially Western Europe, led to increased international competition among the AI companies in the 1990s. In many cases, elite bulls being progeny tested in the United States had full brothers being progeny tested in Europe. The heavy use of a few key sire lines internationally also led to a global Holstein population that is now quite closely related.

As the AI industry in the United States evolved from regional to national to international businesses, the industry simultaneously went through various consolidations, acquisitions, and mergers. A noticeable change from 1981 is the reduction in the number of major AI companies in the United States. In 1981, 11 AI companies produced $90 \%$ of the semen processed in the United States, as reported to NAAB. Today, that same $90 \%$ of the semen produced and reported to NAAB is from only 5 AI companies. These 5 companies include 3 large cooperatives (Select Sires, Genex Cooperative, and Ac- 
celerated Genetics), 1 privately held company (Alta Genetics, with ownership in the Netherlands), and 1 publicly traded company (ABS Global, traded on the London Stock Exchange as Genus plc).

The ownership of Alta Genetics and ABS Global highlights one of the other major changes in the AI industry-globalization. The AI companies today have either business affiliates in, or marketing alliances with, most key cattle-breeding countries around the world.

What factors contributed to this rapid growth and subsequent consolidation and globalization of the AI industry? Although the dynamics are complex, the broad answer to this question is relatively simple: lots of semen available from bulls that are difficult to differentiate by genetics. Because the AI companies were unable to develop a truly differentiated, proprietary product line, some companies tried to grow market share by reducing semen prices. Not wanting to lose customers or market share, competing AI companies often responded by lowering semen prices even further. The AI companies were faced with finding ways to reduce costs, and the consolidation movement was underway and continues today. The inability to develop a differentiated product is not due to lack of trying, as the AI companies have invested millions of dollars into their research and development programs in an effort to do just that. However, various biological, scientific, and industry factors have complicated the effort and will be discussed here in more detail.

\section{SEMEN SUPPLY}

The bovine AI industry grew rapidly following the development of techniques to freeze and store bovine semen in the early 1950s. Some would argue that frozen semen was the last truly innovative technology to have a revolutionary impact on the $\mathrm{AI}$ industry. Before frozen semen, all semen was processed as fresh semen and cows needed to be bred with the semen within 1 or $2 \mathrm{~d}$ of collection. Because of the short lifespan of the fresh semen, shipping semen long distances was prohibitive. That all changed with frozen semen, as time and distance were no longer limiting factors. By 1965, almost all semen produced in the United States was frozen. Frozen semen has been the primary product line for the AI companies for $50 \mathrm{yr}$.

Bulls are great manufacturers of sperm. A healthy mature bull can produce 40 billion or more sperm cells per week, or more than 2 trillion sperm cells per year. The AI companies normally put approximately 15 million total sperm cells in a straw, although the total cells can vary upwards or downwards depending on the quality of the bull's sperm. Most healthy bulls, if kept on a continuous semen collection schedule, can produce over 100,000 straws of frozen semen per year, and it is not uncommon for some bulls to produce 150,000 or more straws of frozen semen per year. Even at a $33 \%$ conception rate, a bull producing 150,000 straws of frozen semen per year could produce 50,000 offspring in $1 \mathrm{yr}$. The extreme reproductive efficiency of bulls via frozen semen has been a contributing factor to the consolidation and globalization of the AI industry, as relatively few bulls can breed thousands of cows, and it is easy to transport frozen semen to practically anywhere in the world.

\section{EXPORT GROWTH}

Progeny-test programs implemented by the AI companies in the 1950s combined with improved genetic evaluation procedures were successful at identifying superior genetic merit bulls, especially for milk production. Early importations of North American Holstein semen into Europe in the 1960s and 1970s resulted in reports that the dairy cattle sired by the North American sires were significantly superior to the local Black and White population for dairy performance.

In the 1970s, Maria Stolzman and colleagues in Poland designed a large-scale FAO breeding trial in Poland in an attempt to quantify differences between strains of Friesians. Ten countries provided semen for the trial: Canada, United States, Denmark, United Kingdom, Sweden, (West) Germany, the Netherlands, Poland, Israel, and New Zealand. The design was for each country to supply 225 to 250 straws of frozen semen from each of 40 nonproven young sires. Results indicated that daughters sired by bulls from North America, Israel, and New Zealand were superior in performance to daughters sired by the bulls from the Western European countries, especially for yield traits. Although some may argue that the experimental design may have been biased (i.e., were the 40 young sires from each country really a representative sample of that country's Friesian population?), the impact on the AI industry was dramatic. The export of North American Holstein semen around the world accelerated.

The 1980s and early 1990s were growth years for the AI companies. As export markets grew, the AI companies reinvested in their development programs and progeny tested additional bulls. The number of Holstein young sires progeny tested by the major AI organizations in the United States is shown in Figure 1.

By the mid 1990s, the number of bulls that were progeny tested peaked and then began to decline. The AI companies were facing more intense competition from foreign AI companies, and the export market began to level off. Many developed dairy countries had imported several generations of elite North American 
1364

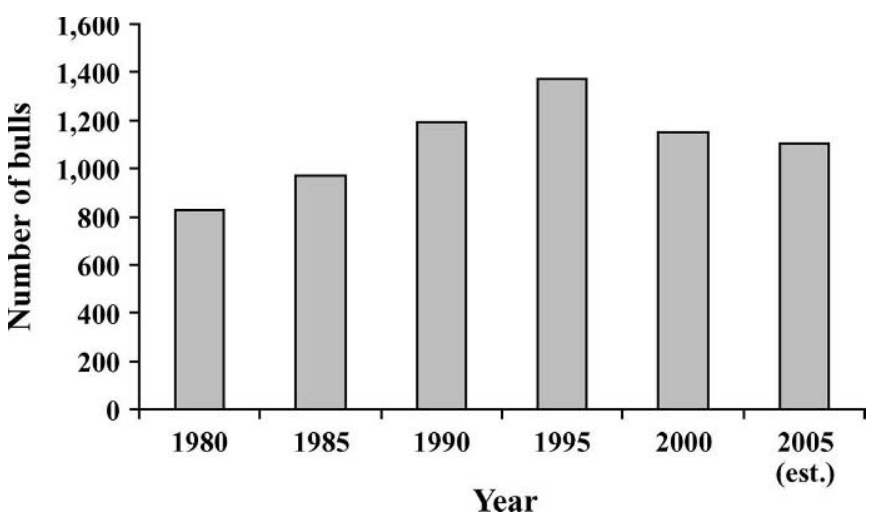

Figure 1. Number of Holstein bulls progeny tested by major AI organizations in the United States from 1980 to 2005 (estimated). Adapted from Norman et al. (2001).

genetics by this time, and there was no longer much difference in the pedigrees of bulls progeny tested in Europe compared with the United States.

\section{INTERNATIONAL SIRE RANKINGS}

Researchers had been working on various statistical procedures to compare the genetic merit of bulls across countries. Initially, most countries used conversion formulas to determine the genetic merit of bulls from a foreign country. Conversion formulas were essentially regression equations using the genetic values for bulls with daughter proofs in each of 2 countries. Animal breeders subsequently developed statistical procedures called multiple across-country evaluations (MACE). The MACE procedures had more desirable statistical properties than conversion formulas, and efforts were undertaken to evaluate bulls from multiple countries simultaneously using MACE.

In 1983, an international research organization was established in Uppsala, Sweden, called the International Bull Evaluation Service (Interbull). The initial objective of Interbull was to develop procedures to collect, standardize, and publish information on the methods used by various countries to calculate sire evaluations. In the early 1990s, efforts were underway to have international evaluations calculated for bulls from all member countries at Interbull using MACE. The United States became a participant in Interbull and in 1995, the United States replaced conversion equations with Interbull MACE for European bulls.

Interbull is still in existence today, and is currently is a joint venture between the International Committee for Animal Recording (ICAR), the European Association for Animal Production (EAAP), and the International Dairy Federation (IDF). Over 40 countries currently

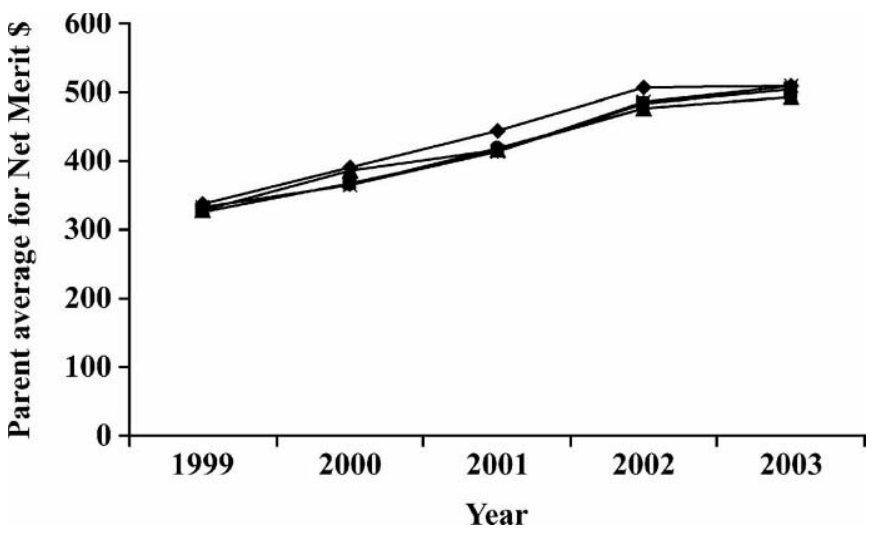

Figure 2. Mean of parent average for Net Merit $\$$ for Holstein bulls progeny tested by the 5 major AI companies in the United States from 1999 to 2003 . $\bullet$ Stud A, $\boldsymbol{\square}=$ Stud B, $\boldsymbol{\Delta}=$ Stud C, $\boldsymbol{\bullet}=$ Stud D, * = Stud E. Source: www.aipl.arsusda.gov.

are members of Interbull, which provides MACE proofs for production, conformation, and udder health for Ayrshire, Brown Swiss, Guernsey, Holstein, Jersey, and Simmental breeds. Efforts are underway at Interbull to provide MACE for additional health and fitness traits, such as fertility and calving ease.

\section{SELECTION OF PARENTS}

Another reason why the AI companies expanded their progeny test programs in the 1980s and early 1990s was that the companies were trying to identify geneticoutlier proven bulls by progeny testing more bulls. The reason that genetic-outlier proven bulls were so important to the AI organizations was that a majority of the revenue generated through semen sales usually came from only a handful of proven bulls. Because mature, proven bulls can be great semen-producing factories, genetic-outlier bulls that demand a higher price than less differentiable, lower genetic merit bulls were desired.

The genetic evaluations in the United States for cows and bulls were readily available and easily accessed by all of the AI companies. Breeders supplying bulls to the AI companies often provided bulls to each of the companies. Although the AI companies might have had minor differences in the selection indices for progenytest bulls, the same maternal and paternal families were used extensively by all of the AI companies. Figure 2 highlights the similarity in average pedigree merit of Holstein young sires that were progeny tested in recent years by the 5 major AI companies in the United States.

Although the means for parent averages are similar, the whole purpose of progeny testing is to identify those bulls that received a superior sample of genes from 
parents through gene segregation. The odds of finding a genetic outlier via gene segregation, given that the pedigree start points are all the same, becomes a function of the number of bulls tested. By progeny testing more bulls, the AI companies had a better chance of identifying a genetic-outlier proven bull.

But with more bulls progeny tested, there were subsequently more proven bulls, and the odds of finding a genetic outlier relative to the total bulls sampled became lower given that the bulls were all being sourced from a relatively small, and similar, pool of parents.

\section{MULTIPLE OVULATION EMBRYO TRANSFER}

In the 1980s, some AI companies attempted to differentiate their genetics by taking more ownership of the female side of the pedigree. Embryo transfer (ET) had become a more common practice amongst breeders of elite genetics, and structured breeding programs that capitalized on maximizing genetic progress through embryo transfer were generically called multiple ovulation embryo transfer (MOET) programs. Using simulation models, researchers concluded that genetic progress could be accelerated by implementing MOET programs. Among MOET programs considered were open MOET programs (continue incorporation of new females from outside the MOET), closed MOET (utilization of females generated from with the MOET only), and juvenile MOET (maximizing the use of younger parents in the MOET).

Highly structured MOET programs where the AI companies purchased females and managed the females were established by some of the European AI companies, but not by the AI companies in the United States. In a broad sense, the AI companies in the United States operate very disperse MOET programs, working with cooperator breeders to flush elite females for bulls. A few AI companies in the United States own some females, but no AI organization in the United States has built milking facilities for a structured MOET program, with the exception of Alta Genetics, which has a dairy herd in Canada that has been owned for many years by the principal owner of Alta Genetics. Structured MOET operations require a great deal of upfront capital to build facilities, and the AI companies probably viewed such investments as high risk, especially given the competitive nature of the AI business in the United States.

\section{PROGENY TEST}

One of the biggest development costs for the AI companies in the United States is the progeny-test program. The AI organizations estimate that the total cost associated with progeny testing a Holstein young sire ranges from $\$ 25,000$ to $\$ 35,000$ per bull. The percentage of bulls that graduate from the progeny-test program into the proven bull line-up is about $12 \%$. Assuming an average investment of $\$ 30,000$ per young sire, the AI companies invest about $\$ 250,000$ per graduate.

The investment into expanded progeny-test programs was easy to justify during the rapid growth in export sales during the 1980s and early 1990s, but as the export market softened due to growing international competition in the mid 1990s, the continued expansion in progeny test was less easy to justify from a business perspective.

\section{GENETIC MARKERS}

In the 1990 s, several of the AI companies invested in genetic marker technology, primarily in an attempt to more efficiently identify which young sire amongst a litter of full brothers had received the more optimal gene sample from his parents. A short-term objective was to improve the success rate by having a higher proportion of proven-bull graduates than did the competitors. A long-term objective was to reduce progenytest costs by sampling fewer bulls because of higher graduation rates than their competitors. Two of the AI companies developed DNA laboratories to collect and analyze DNA, whereas some of the others subcontracted DNA analyses with outside research centers.

Genetic markers and gene tests have been used extensively to test animals for qualitative traits over the past $25 \mathrm{yr}$, especially for deleterious recessive genes. The tests have allowed for rapid screening of breeding stock for different recessive genes. The Holstein breed dealt with 2 lethal recessive genes in the last $15 \mathrm{yr}$ that were widespread throughout the breed, first bovine leukocyte adhesion deficiency (BLAD) and later complex vertebral malformation (CVM). Both of these recessives trace back to a popular Holstein bull born in 1974 that was used heavily in global breeding programs, Carlin-M Ivanhoe Bell. For both BLAD and CVM, the gene responsible for the disorder was quickly identified, and a definitive gene test allowed breeders to determine the genotype of their animals. In both cases, AI companies voluntarily discontinued progeny testing young sires known to be carriers of these 2 lethal genes, and the gene frequencies of these lethal genes in the population have or will rapidly decline within a few generations.

Other deleterious and lethal genes have not been as easy to find. For example, the chromosomal region harboring mulefoot in Holsteins and other breeds has been known for many years, but the specific gene has not yet been identified. Chromosome crossover, or re- 
combination, is needed to narrow the region, although the region is small enough that frequency of recombination is rare. However, as long as the entire region is inherited intact as determined by several markers in the region, one can be reasonably confident about the inheritance of the gene. The gene for the Weaver condition in Brown Swiss cattle has also been mapped to a chromosomal region, but the specific gene remains elusive.

For quantitative traits, genetic markers have had minimal, if any, impact on the AI industry to date. Most of the initial data analyzed with genetic markers were production data. The production data were readily available, and in the $1990 \mathrm{~s}$, production traits were weighted heavily in the selection indices, and thus, were obvious candidate traits to study. Dairy cattle data were perfectly suited for granddaughter analyses, and the most influential grandsire families were studied. Researchers quickly identified chromosomes of interest for production traits, and certain regions within those chromosomes appeared to include a major gene or genes for production traits. Some regions were specific to individual sire families, whereas others appeared to be significant across families.

Despite the rapid discovery of chromosomal regions of interest for production traits, finding the specific genes has been more difficult. Perhaps gene function associated with quantitative traits such as production is more complex than originally thought. Combining all of the genetic marker data with the population genetics data to arrive at an overall breeding value was also computationally complex.

ABS Global implemented selection of young sires enhanced by genetic marker information, mostly for production traits, from 1997 to 2000 . Markers were identified from a granddaughter design and were mostly series of markers upstream and downstream from the hypothesized gene site. This was before dense genotyping, and recombination was relatively common in subsequent generations, making the interpretation of gene inheritance difficult for many of the young sires. The graduation rate $(12 \%)$ for the 70 young sires selected with genetic markers was the same as for the 500 young sires that were not selected using markers. The early implementation of markers for production traits that covered wide chromosomal regions did not achieve the anticipated objective of higher graduation rates for ABS Global. Conversely, Accelerated Genetics reports that the use of genetic markers in their young sire selection programs has improved their graduation rate.

Applying the genetic marker results to a selection program was complicated by additional factors. Sample sizes were often small. The full-brother with the best genetic markers for production sometimes failed his health test, did not produce semen, or was physically unsound. To validate that the markers were successful required that at least one of the full brothers was progeny tested, and in many cases, only one brother from the litter was progeny tested. This reduced the number of bulls that could be included in the genetic marker subset.

By 2000, most of the AI companies had started to put less selection pressure on production traits so that additional selection pressure could be put on various health, fitness, and conformation traits, such as productive life (PL), somatic cell score (SCS), and udder composite (UC). Although researchers have identified genetic markers for some of these nonproduction traits, there are fewer marker results available for nonproduction traits than for production traits. A challenge remains on how to optimally combine all of the available marker and population data together for both production and nonproduction traits to arrive at a composite breeding value that can be used for selection.

\section{SELECTION FOR NONYIELD TRAITS}

The extensive amount of genetic progress that the dairy breeds have made for yield traits over the last $25 \mathrm{yr}$ is well documented. However, breeders began expressing more and more concern about nonyield traits in recent years. The evolution away from heavy emphasis on production traits in the United States to more emphasis on nonproduction traits is reflected in the changes over time in various indices used by the industry to determine overall genetic merit, as shown in Table 1.

Initially, emphasis in the various indices for overall merit was shifted from production traits to conformation traits, as conformation data were available and were thought to be indicator traits for increased dairy function. In the mid 1990s, the USDA began calculating genetic evaluations for PL and SCS, and these more direct measures for health and fitness traits were incorporated in the overall merit indexes. More recently, additional direct measures for various health and fitness traits were incorporated directly. The AI companies continue to work with herds participating in progeny testing to record and collect additional nonyield data.

In particular, fertility emerged as a growing management challenge in high-producing dairy herds around the world. Days open for Holsteins in the United States has increased by $40 \mathrm{~d}$ since 1960, and the genetic proportion of this reproductive decline in days open is estimated at $16 \mathrm{~d}$. The successful selection for production traits appears to have depressed reproductive performance in dairy cattle. Although improved management 
Table 1. Relative emphasis on traits in USDA economic indices for PD $\$$, MFP $\$$, CY $\$$, and NM $\$$, and Holstein Association TPI over time ${ }^{1}$

\begin{tabular}{|c|c|c|c|c|c|c|c|c|c|c|}
\hline \multirow[b]{2}{*}{ Trait } & \multicolumn{10}{|c|}{ Index $^{2}$ (year of introduction) } \\
\hline & $\begin{array}{l}\mathrm{PD} \$ \\
(1971)\end{array}$ & $\begin{array}{l}\text { TPI } \\
(1976)\end{array}$ & $\begin{array}{l}\text { MFP\$ } \\
(1977)\end{array}$ & $\begin{array}{l}\text { TPI } \\
(1980)\end{array}$ & $\begin{array}{l}\text { CY\$ } \\
(1984)\end{array}$ & $\begin{array}{l}\text { TPI } \\
(1989)\end{array}$ & $\begin{array}{l}\text { NM\$ } \\
(2000)\end{array}$ & $\begin{array}{l}\text { TPI } \\
(2000)\end{array}$ & $\begin{array}{l}\text { NM\$ } \\
(2003)\end{array}$ & $\begin{array}{l}\text { TPI } \\
(2004)\end{array}$ \\
\hline Fat & 48 & & 46 & & 45 & 34 & 21 & 16 & 22 & 18 \\
\hline Milk & 52 & 60 & 27 & 60 & -2 & & 5 & & & \\
\hline Fat $\%$ & & & & 20 & & & & & & \\
\hline Longevity & & & & & & & 14 & 13 & 11 & 8 \\
\hline Feet/Legs & & & & & & & 4 & 5 & 4 & 5 \\
\hline Size & & & & & & & -4 & & -3 & \\
\hline Final score & & 40 & & 20 & & 17 & & 14 & & 13 \\
\hline Dairy form & & & & & & & & & & -2 \\
\hline Daughter pregnancy rate & & & & & & & & & 7 & 5 \\
\hline Service sire calving ease & & & & & & & & & -2 & \\
\hline Daughter calving ease & & & & & & & & & -2 & -2 \\
\hline
\end{tabular}

${ }^{1}$ Adapted from www.aipl.arsusda.gov/publish/presentations/WC7_02 and T. Lawlor, Holstein Association (personal communication).

${ }^{2} \mathrm{PD} \$=$ Predicted Difference $\$$; TPI = Type Production Index; MFP $\$=$ Milk Fat Protein $\$$; CY $\$=$ Cheese Yield $\$$; and NM $\$=$ Net Merit $\$$; all calculated by USDA.

practices may overcome some of the fertility decline, the data suggest that direct and indirect selection emphasis for reproduction is necessary to slow down the decline in fertility. The linear type trait with the highest relationship with daughter pregnancy rate (DPR) is dairy form. Putting negative selection pressure on extreme dairy form is an initial attempt at using this trait as an indicator trait for improved reproductive performance before the time when the more direct measure of DPR is available.

\section{INBREEDING}

The ease with which a few bulls can be used heavily in global breeding programs to develop elite breeding stock has led to a rapid increase in inbreeding levels in recent years, especially for the Holstein and Jersey breeds. The inbreeding trend for Holsteins in the United States is illustrated in Table 2.

The negative influence of inbreeding depression is well documented and may be a contributing factor to the decline in fertility, so it would be logical that the

Table 2. Estimated and projected average inbreeding percentage of US Holstein population ${ }^{1}$

\begin{tabular}{ll}
\hline Year & $\begin{array}{l}\text { Average } \\
\text { inbreeding, \% }\end{array}$ \\
\hline 1970 & 2.7 \\
1980 & 4.6 \\
1990 & 5.4 \\
2000 & 6.8 \\
2010 & 8.2 \\
2020 & 9.7 \\
\hline
\end{tabular}

${ }^{1}$ Adapted from Young and Seykora (1996) and Hansen (2000).
AI companies in the United States would have an aggressive program to diversify the pedigrees of young sires to reduce the increasing rate of inbreeding. Although the AI companies in the United States realize that growing levels of inbreeding within the dairy breeds are a concern, little has been done to address the issue to date. The probable reason for lack of action by the AI companies is that initial efforts to progeny test less-related young sires, generically called outcross sires, have not resulted in much financial success. The highly competitive nature of the industry, and the large costs associated with progeny test, caused the AI companies to mostly sample only the highest genetic merit young sires, and these bulls tend to be highly related to the breed.

Current evaluation and progeny-testing procedures tend to work to the disadvantage of outcross young sires. The outcross sire usually has a lower parent average, so the progeny test must include enough daughters for the young sire to overcome this lower pedigree start point. As more emphasis is placed on lower heritability traits and less emphasis is placed on higher heritability production traits in the genetic indices for overall merit, it will become even more difficult to identify an outcross proven bull through the progeny-test program. Lastly, the response from customers in the marketplace for outcross bulls has generally been lukewarm, not a strong endorsement for the AI companies to risk sampling many lower genetic merit, outcross pedigrees.

\section{CROSSBREEDING}

Although crossbreeding is common in the beef cattle industry and most other production livestock species, 
crossbreeding in dairy cattle has not been widespread in the United States. In just the last few years, however, there has been a great deal of interest in crossbreeding, driven in large part by breeders wanting to improve the hybrid vigor of their cows and heifers, especially for fertility, health, and calf livability. Most AI organizations in the United States have Holsteins, Jerseys, and Brown Swiss bulls, and Ayrshire and Guernsey bulls are also available from a few of the organizations.

However, several European dairy breeds not commonly found in the United States are now being marketed, primarily to cross on Holstein cows. Among the breeds being imported for crossbreeding are Montbéliard, Normande, and the Scandinavian Red breeds. The growth of crossbreeding in dairy cattle will likely result in the AI companies in the United States developing additional international business collaborations.

\section{CONCLUSIONS}

A few mega-trends are apparent. The AI industry in the United States will go through more consolidations in an effort to maximize synergies and minimize costs. With only a few AI companies remaining in the United States, most consolidations and mergers will now involve foreign companies. Selection emphasis will continue to shift from production traits to nonproduction traits as breeders and AI companies attempt to breed for long-lasting, durable, and profitable dairy cattle. Fertility is perhaps the biggest genetic and management challenge facing dairy operations in the United States today and the AI organizations will need to put additional selection emphasis on this trait. Inbreeding levels will continue to rise within the purebred dairy breeds in the United States, and crossbreeding will become a more common practice to overcome inbreeding depression within the pure breeds.

\section{REFERENCES}

Ashwell, M. S., C. P. Van Tassell, and T. S. Sonstegard. 2001. A genome scan to identify quantitative trait loci affecting economi- cally important traits in a US Holstein population. J. Dairy Sci. 84:2535-2542.

DeJarnette, J. M., C. E. Marshall, R. W. Lenz, D. R. Monke, W. H. Ayars, and C. G. Sattler. 2004. Sustaining the fertility of artificially inseminated dairy cattle: The role of the artificial insemination industry. J. Dairy Sci. 87(E. Suppl.):E93-E104.

Foote, R. H., 1996. Dairy cattle reproductive physiology research and management-Past progress and future prospects. J. Dairy Sci. 79:980-990.

Hansen, L. B. 2000. Consequences of selection for milk yield from a geneticist's viewpoint. J. Dairy Sci. 83:1145-1150.

Hasler, J. F., 1992. Current status and potential of embryo transfer and reproductive technology in dairy cattle. J. Dairy Sci. $75: 2857-2879$.

Meinert, T. R., H. D. Norman, J. M. Mattison, and C. G. Sattler. 1997. Usability for genetic evaluations of records from herds participating in progeny test programs of artificial insemination organizations. J. Dairy Sci. 80:2599-2605.

Miller, P. D. 1981. Artificial insemination organizations. J. Dairy Sci. 64:1283-1287.

Miller, P. D. 1988. Implementing technology for genetic improvement: Industry's view. J. Dairy Sci. 71:1967-1971.

Nicolas, F. W., and C. Smith. 1983. Increased rates of genetic change in dairy cattle by embryo transfer and splitting. Anim. Prod. 36:341-348.

Norman, H. D., R. L. Powell, J. R. Wright, and C. G. Sattler. 2001. Overview of progeny-test programs of artificial-insemination organizations in the United States. J. Dairy Sci. 84:1899-1912.

Norman, H. D., R. L. Powell, J. R. Wright, and C. G. Sattler. 2003. Timeliness and effectiveness of progeny testing through artificial insemination. J. Dairy Sci. 86:1513-1525.

Powell, R. L., H. D. Norman, and A. H. Sanders. 2003. Progeny testing and selection intensity of Holstein bulls in different countries. J. Dairy Sci. 86:3386-3393.

VanRaden, P. M. 2002. Subject: Selection of dairy cattle for lifetime profit. Online. Available at: http://www.aipl.arsusda.gov/publish/ presentations/WC7_02/pvrWC_files/frame.htm Accessed Aug. 30, 2005.

VanRaden, P. M. 2003. Genetic evaluations for fitness and fertility in the United States and other nations. Pages 103-106 in Proc. Natl. Dairy Genetics Workshop, Raleigh, NC. Virginia Polytechnic Inst. State Univ., Blacksburg.

VanRaden, P. M., A. H. Sanders, M. E. Tooker, R. H. Miller, H. D. Norman, M. T. Kuhn, and G. R. Rogers. 2004. Development of a national genetic evaluation for cow fertility. J. Dairy Sci. 87:2285-2292.

VanRaden, P. M., and A. J. Seykora. 2003. Net merit as a measure of lifetime profit: 2003 revision. AIPL Res. Rep. NM\$2 (7-03). Online. Available at: http://www.aipl.arsusda.gov/reference/ nmcalc.htm. Accessed August 30, 2004.

Young, C. W., and A. J. Seykora. 1996. Estimates of inbreeding and relationship among registered Holstein females in the United States. J. Dairy Sci. 79:502-505.

Zarnecki, A., and M. Stolzman. 1986. A preliminary comparison of later lactation yield of different Friesian strains in Poland. Proc. 3rd World Congr. Genet. Appl. Livest. Prod. IX:112-114. 